\title{
An Overview on the Current Status and Future Perspectives of Smart Cars
}

\author{
Fabio Arena ${ }^{1} \mathbb{D}$, Giovanni Pau ${ }^{1, * \mathbb{D}}$ and Alessandro Severino ${ }^{2}$ \\ 1 Faculty of Engineering and Architecture, Kore University of Enna, 94100 Enna, Italy; fabio.arena@unikore.it \\ 2 Department of Civil Engineering and Architecture, University of Catania, 95123 Catania, Italy; \\ alessandro.severino@unict.it \\ * Correspondence: giovanni.pau@unikore.it
}

Received: 29 May 2020; Accepted: 28 June 2020; Published: 30 June 2020

\begin{abstract}
In recent years, the smart car sector has been increasing enormously in the Internet of Things (IoT) market. Furthermore, the number of smart cars seems set to increase over the next few years. This goal will be achieved because the application of recent IoT technologies to the automotive sector opens up innovative opportunities for the mobility of the future, in which connected cars will be more and more prominent in smart cities. This paper aims to provide an overview of the current status and future perspectives of smart cars, taking into account technological, transport, and social features. An analysis concerning the approaches to making smart a generic car, the possible evolutions that could occur in the coming decades, the characteristics of 5G, ADAS (advanced driver assistance systems), and the power sources is carried out in this paper.
\end{abstract}

Keywords: smart car; self-driving car; connected car; Internet of Things; smart city

\section{Introduction}

The smart car can be recognized as a mix between the self-driving car and the connected car [1,2]. It cannot only drive autonomously but, thanks to the Internet connection, can share the access to the network with passengers and allow the usage of its data to devices that are located inside or remotely [3]. In a short time, it will be possible to misremember "the old metal box on four wheels" because the cars that will be driven shortly will be smarter and will allow performing actions unimaginable until recently [4]. The car will no longer be a mere means of transport because, thanks to new technologies, it will be able not only to simplify the driver's life but also to increase safety on the road [5-7].

First of all, the smart car is a self-driving car whose automation level $[8,9]$, as shown in Figure 1, is high (level 4) or complete (level 5). In the first case, it is a substantially full autonomous driving, in which the vehicle can perform all the essential functions of safety and regularly monitor road conditions for the entire trip, but not in extreme weather conditions. In the second case, instead, only the indication of the destination and the start of the system is required, without any other intervention by the driver, in all possible cases. Besides, the smart car is a connected car part of the Internet of Things (IoT) that now pervades any area of everyday life $[10,11]$. In fact, in addition to allowing motorists to access, generally through the smartphone, to information concerning the state of the car, its location, and technical data, smart cars are also able to warn emergency services in the event of an accident, to contact the workshop if something in the engine does not go as it should, to inform the tire dealer if it is punctured. 


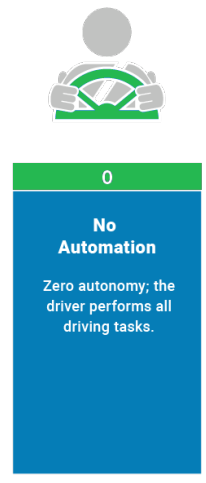

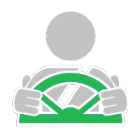

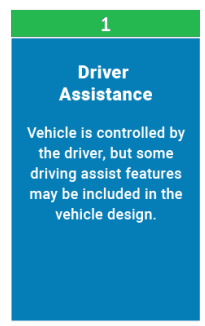

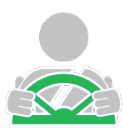
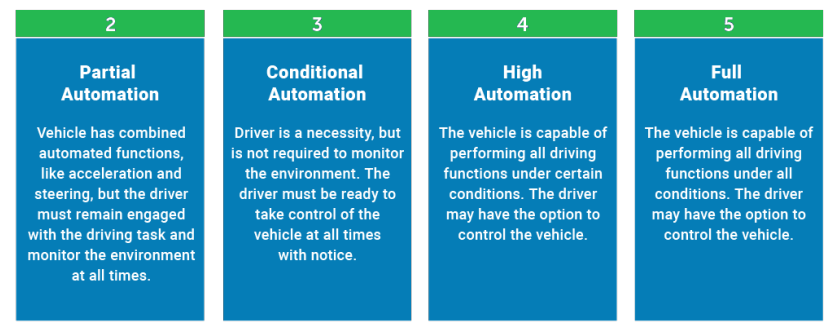

Figure 1. Vehicle automation levels.

However, a significant difficulty to be faced in the development of driverless vehicles concerns the skills of the passenger [12]. In fact, should he/she be only transported or could he/she decide from time to time? As every commuter knows, everyday driving is often dull, and being a mere passenger can be even more so. Furthermore, there are still many problems to be solved, so that the massive diffusion of the autonomous vehicles $(\mathrm{AV})$ is realized: here are five issues that must be resolved before autonomously driven cars can take diffusion furrow the roads [13]:

- Higher performance and redundant software;

- More advanced and capillary maps;

- More efficient and precise sensors;

- Better vehicle-to-vehicle (V2V) and vehicle-to-infrastructure (V2I) communications [14].

Fortunately, several nations of the world are now focusing on smart car technologies. Among these, the United States certainly plays a predominant role. On the contrary, in Europe, the United Kingdom and the Netherlands are also stimulating research in this area. The real breakthrough will, however, have to be carried out by car manufacturers. Most of them plan to test the market with autonomous vehicles of level 3 or possibly level 4 around 2021. Such AV will still have steering wheels and pedals and can be driven autonomously only on pre-established roads [15-17]. Most of these vehicles are likely to be purchased from onboard transit services (Uber and others). Consumers who want the flexibility and freedom of complete level 5 vehicles will have to wait longer. The major car manufacturers (Tesla, General Motors, Ford, Fiat-Chrysler, and Waymo, to name a few of the main ones) like to talk about autonomous vehicles as if they will be on sale in their showrooms in three or four years.

This paper aims to provide an overview of smart cars by presenting the current state of technology and future perspectives. Specifically, Section 2 examines the current status of smart cars and how it is possible to make a car potentially smart. Section 3 presents the strict relationship between smart cars and future $5 \mathrm{G}$ connections. Section 4 introduces the future perspectives of smart cars by analyzing ADAS (advanced driver assistance systems) in detail and also the possible evolutions of the engines. Finally, Section 5 concludes the paper.

\section{Current Status}

The smart car can drive autonomously and holds an Internet connection, thanks to which can share the network access with passengers. Moreover, it is possible to access specific parameters through devices located inside the car and remotely [18]. Once connected, the smart car can communicate with satellite navigation systems to share traffic data, and at the same time, receive the proper information to suggest deviations from the route as a way to avoid the queues. Thanks to the services available on smartphones, the smart car can also turn on the air conditioning a few minutes before the driver arrives to refresh or heat the passenger compartment or turn on the lights remotely to be identified in a crowded parking lot, or be located in the event of theft [19]. Some operating systems for connected cars 
also have concierge systems. For instance, while on the street, it is possible to book a hotel, a parking space, or a restaurant near the destination. Furthermore, it is conceivable to program the overhaul or mechanical interventions for cases of breakdowns, in which the car itself is to report both to the owner and the partner workshops [20].

A real smart car that is fully autonomous and connected will arrive on roads shortly. At present, there are several solutions to make a car smart enough. Starting from the latest arrival, Echo Auto is the artificial intelligence of Alexa (Amazon's assistant) transformed to adapt to the needs of motorists [21]. As big as a standard portable charger, this device connects to the car via Bluetooth or with an audio cable and works by installing the interface through an app on the smartphone and connecting it to the car speaker. Like Alexa at home, Echo Auto recognizes the motorist's voice by filtering out background noises and can be used both as a voice command service and as a navigation system thanks to the integration with Apple Maps, Google Maps, and Waze.

Less connected but just as smart are various hardware devices that carry head-up display (HUD) technology in the car [22], the same used for years on military aircraft to show onto the windshield information about navigation. Several devices combinable with smartphones can be purchased online. They act in practice like mirrors, showing on a vertical surface to be positioned on the dashboard. In this case, software solutions are needed, which are now effortlessly found both on the App Store for iOS and on the Google Play Store for Android, which by using the sensors of the phone and the GPS can project data such as maps, speed, and car acceleration; weather forecasts; and any other functions that may be useful during a trip by car, including infotainment. A slightly more complex solution is represented by apps that connect to an adapter inserted in the car's on-board diagnostics (ODB) port. Once the adapter is configured, the app allows viewing data such as distance traveled, speed, fuel level, average consumption, and engine status. The app then works as a diagnostic system.

\section{5G and Connected Cars}

As the automotive industry continues to accelerate the development of connected cars, other Internet of Vehicles (IoV) solutions are emerging through advances in networking, 5G, and IoT. Traditional car manufacturers need to take on additional roles beyond merely making cars and becoming service providers for cars. A possible representation of the $\mathrm{IoV}$ architecture is shown in Figure 2. With IoV and more excellent connectivity, the development of innovative industry applications now offers management features for data, interconnections, operations, and security, opening a variety of APIs (Application Platform Interface) for third-party solutions. As shown in Figure 2, there must be an intrinsic synergy between the sensors, the computation, and the applications used by users. The sensors will involve not only vehicle monitoring but also the gathering of information from the surrounding environment. The computation will also be related to the transmission of information using short or long-distance communications, also taking advantage of the processing in the cloud, in the edge and artificial intelligence techniques. 5G will undoubtedly play a fundamental role in this infrastructure.

Some specifications of the $5 \mathrm{G}$ standard are still being defined, but it is already known that telecommunications will change as never before [23]. The 5G, with a theoretical bandwidth from $100 \mathrm{Mbps}$ to $10 \mathrm{Gbps}$, reduced energy consumption, enormously decreased latency time, and unprecedented reliability, will be the network that will connect the world of tomorrow [24]. It is essential for smart cars. The ultrafast band is capable of using the Internet at very high speeds and bringing a series of previously unthinkable services. This new connectivity will introduce the Vehicle-to-Everything (V2X) [25-27] communication to facilitate the exchange of data between cars in milliseconds and within $500 \mathrm{~m}$ [28]. The services available are varied. It can be possible to share information on traffic conditions. In case of danger, a signal can be sent to the other cars, reporting an accident, with its precise coordinates, or a traffic light can indicate its status to the car, and road signs can still report the speed limit [29]. For instance, the Forward Collision Warning (FCW) [30] detects the danger of a potential frontal collision and 
alerts the driver. In this specific case, the Intersection Movement Assist (IMA) [31,32] assists the driver near the intersections, preventing a potential side collision with an arriving vehicle.

Sensing: environment and control layer

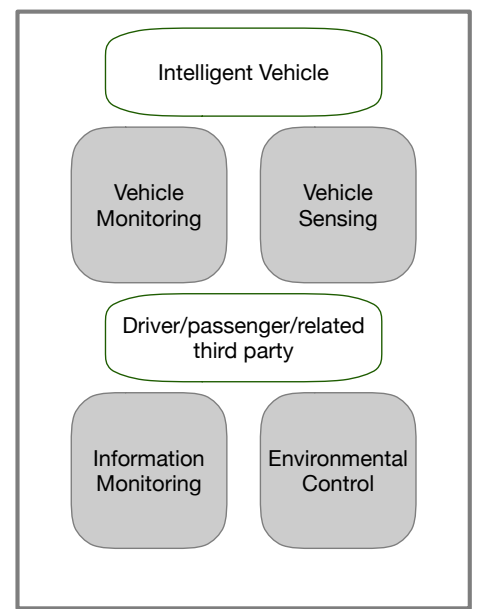

Computing layer

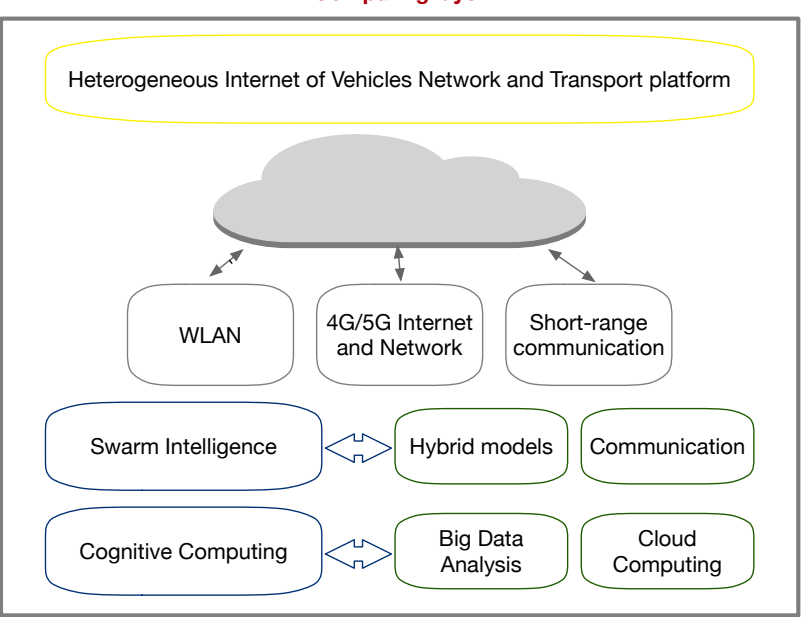

Application layer

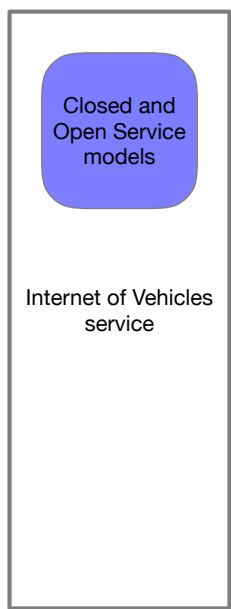

Figure 2. Basic components of Internet of Vehicles architecture.

The 5G network can help protect vulnerable road users; i.e., pedestrians (their presence on a crossing) and cyclists (the presence of a connected bicycle on the road). For instance, in the case of a pedestrian preparing to cross the road, a device on the roadside, connected to the mobile network and equipped with a camera capable of detecting the action, sends an alert message to the connected vehicles in the proximity. This situation represents infrastructure-to-vehicle (I2V) communication [9]. In the scenario represented by a connected bicycle and vehicle, moving towards each other, in case of detection of the risk of collision, both receive an alert message on the presence of the other vehicle. The 5G specifications can also facilitate the exchange of streaming video between vehicles in real-time, widening the driver's field of vision in contexts of limited visibility and preventing accidents, especially during the overtaking phase [33]. A possible configuration of a 5G-enabled architecture for V2V communications is shown in Figure 3. In this case, 5G would deal with communication on a larger scale while the vehicles between them could use a protocol belonging to the IEEE 802.11 family.

Concerning the fast and reliable exchange of information between vehicles in an emergency case, the ultra-fast network facilitates two operations:

- Stationary vehicle warning (SVW) [34]: when the emergency lights are activated, the application transmits a message to all the vehicles in the proximity, to inform the arriving ones, even if the emergency circumstance is not still visible;

- Emergency electronic brake light (EEBL) warning [35]: in the event of sudden braking, the application transmits a message to the rear vehicles, to communicate the potentially dangerous situation to the arriving ones.

Smart cars, commercial 5G smartphones, and 5G networks will guarantee better comfort, safety, and efficiency [36]. This fashionable collaboration brought together the power of eye-monitoring glasses, smart tires, augmented reality onboard the vehicle, and 5G smartphones in a live synergy on the 5G network. All of this can now make instant the collaborations between vehicles, the Internet of Things ecosystem, and the most advanced driver assistance services possible. Table 1 resumes some potential applications for 5G-enabled vehicles, while possible purposes and downsides are depicted in Table 2. Moreover, most relevant details concerning key building blocks of 5G and their associated challenges in the context of vehicular communications are summarized in Table 3. 


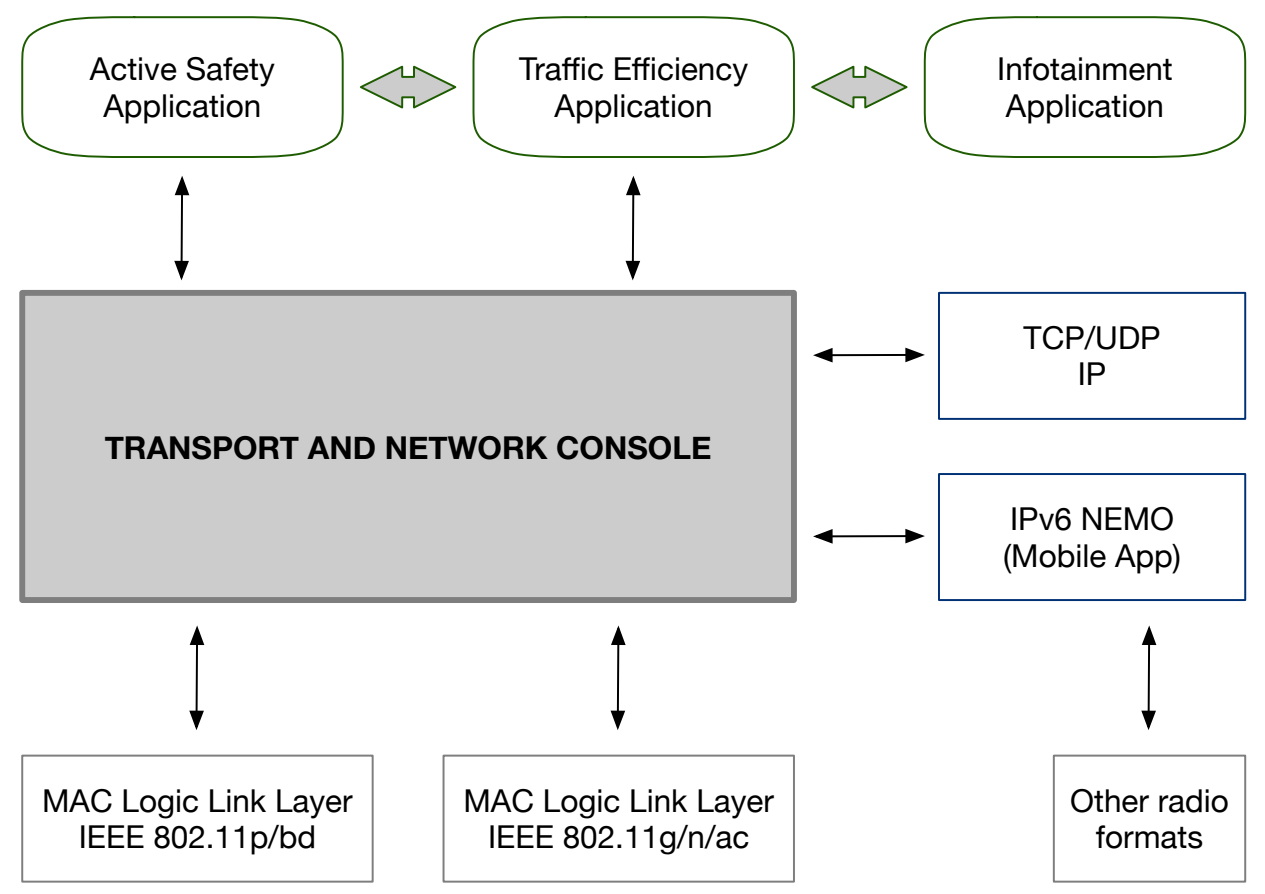

Figure 3. Possible architectural configuration of a 5G-enabled vehicle-to-vehicle (V2V) communication.

Table 1. Fascinating potential applications for 5G-connected vehicles.

\begin{tabular}{|c|c|c|}
\hline V2V Safety & Agency Data/Environment & Smart Roadside/Mobility \\
\hline $\begin{array}{l}\text { Emergency Electronic } \\
\text { Brake Lights (EEBL) }\end{array}$ & $\begin{array}{c}\text { Probe-based Pavement } \\
\text { Maintenance }\end{array}$ & Wireless Inspection \\
\hline $\begin{array}{l}\text { Stationary Vehicle } \\
\text { Warning (SVW) }\end{array}$ & $\begin{array}{l}\text { Probe-enabled Traffic } \\
\text { Monitoring }\end{array}$ & Smart Truck Parking \\
\hline $\begin{array}{l}\text { Intersection Movement } \\
\text { Assist (IMA) }\end{array}$ & $\begin{array}{c}\text { Vehicle Classification-based } \\
\text { Traffic Studies }\end{array}$ & $\begin{array}{l}\text { Intelligent Traffic Signal } \\
\text { System (I-SIG) }\end{array}$ \\
\hline $\begin{array}{l}\text { Left Turn Assist } \\
\text { (LTA) }\end{array}$ & $\begin{array}{l}\text { CV-enabled Turning Movement } \\
\text { \& Intersection Analysis }\end{array}$ & $\begin{array}{l}\text { Signal Priority } \\
\text { (transit, freight) }\end{array}$ \\
\hline $\begin{array}{l}\text { Blind Spot/Lane } \\
\text { Change Warning }\end{array}$ & $\begin{array}{c}\text { CV-enabled Origin-Destination } \\
\text { Studies }\end{array}$ & $\begin{array}{l}\text { Cooperative Adaptive } \\
\text { Cruise Control (CACC) }\end{array}$ \\
\hline $\begin{array}{l}\text { Curve Speed } \\
\text { Warning }\end{array}$ & $\begin{array}{l}\text { Work Zone Traveler } \\
\text { Information }\end{array}$ & $\begin{array}{l}\text { Guidance for } \\
\text { Emergency }\end{array}$ \\
\hline $\begin{array}{c}\text { Do Not Pass } \\
\text { Warning (DNPW) }\end{array}$ & $\begin{array}{c}\text { Dynamic Eco-Routing } \\
\text { (light, vehicle, transit, freight) }\end{array}$ & $\begin{array}{l}\text { Emergency Communications } \\
\text { and Evacuation (EVAC) }\end{array}$ \\
\hline $\begin{array}{l}\text { Vehicle Turning } \\
\text { Right in Front of }\end{array}$ & $\begin{array}{l}\text { Low Emissions Zone } \\
\text { Management }\end{array}$ & $\begin{array}{l}\text { Connection Protection } \\
\text { (T-CONNECT) }\end{array}$ \\
\hline $\begin{array}{l}\text { Bus Warning } \\
\quad \text { (transit) }\end{array}$ & $\begin{array}{l}\text { Eco-ICM Decision } \\
\text { Support System }\end{array}$ & $\begin{array}{l}\text { Freight-Specific } \\
\text { Dynamic Travel }\end{array}$ \\
\hline $\begin{array}{l}\text { Queue Warning } \\
\text { (Q-WARN) }\end{array}$ & $\begin{array}{l}\text { Eco-Smart } \\
\text { Parking }\end{array}$ & $\begin{array}{c}\text { Emergency Vehicle } \\
\text { Preemption (PREEMPT) }\end{array}$ \\
\hline
\end{tabular}


Table 2. Some purposes and downsides of future 5G-enabled vehicular communications.

\begin{tabular}{|c|c|c|}
\hline Feature & Advantages & Downsides \\
\hline $\begin{array}{l}\text { Maintenance } \\
\text { of road surface } \\
\text { and signs }\end{array}$ & $\begin{array}{l}\text { - Improvement of ITS } \\
\text { systems performance }\end{array}$ & - Economic costs \\
\hline $\begin{array}{l}\text { Technological } \\
\text { infrastructure }\end{array}$ & $\begin{array}{l}\text { - Full operation of V2V, } \\
\text { V2I, and V2X communications }\end{array}$ & $\begin{array}{c}\text { - Complexity of large-scale } \\
\text { implementation } \\
\text { - Standardization }\end{array}$ \\
\hline $\begin{array}{l}\text { Big Data } \\
\text { management }\end{array}$ & $\begin{array}{l}\text { - Economic returns for } \\
\text { possible private investors } \\
\text { - More information } \\
\text { thanks to analysis }\end{array}$ & - Ensure data privacy \\
\hline $\begin{array}{l}\text { Integration between } \\
\text { ITS systems } \\
\text { and technological } \\
\text { infrastructure }\end{array}$ & $\begin{array}{l}\text { - Improved performance } \\
\text { in system operation } \\
\text { - Development of possible } \\
\text { new future applications }\end{array}$ & $\begin{array}{c}\text { - Complexity of large-scale } \\
\text { implementation } \\
\text { - Standardization } \\
\text { - Economic costs }\end{array}$ \\
\hline
\end{tabular}

Table 3. A summary of $5 \mathrm{G}$ building blocks applicable to vehicular communications.

\begin{tabular}{|c|c|c|}
\hline 5G Building Blocks & Features & Challenges \\
\hline Proximity service & $\begin{array}{l}\text { - Offloads the base station } \\
\text { - User can advertise, discover, and } \\
\text { communicate directly }\end{array}$ & $\begin{array}{l}\text { - Interferences at lower altitudes } \\
\text { - Interferences in same-band transmissions } \\
\text { - Spectrum allocation issues }\end{array}$ \\
\hline Mobile edge computing & $\begin{array}{l}\text { - Bring cloud computing at the edge } \\
\text { - Support multi-vendor environment }\end{array}$ & $\begin{array}{l}\text { - Availability of all access technology } \\
\text { - Cost effectiveness of hosting cloudlets } \\
\text { - Hosting demands (processing, security, etc.) }\end{array}$ \\
\hline Network slicing & $\begin{array}{l}\text { - A management architecture to logically } \\
\text { separate networks } \\
\text { - Provision for multiple control planes } \\
\text { for networks }\end{array}$ & $\begin{array}{l}\text { - A truly modular approach for slicing networks } \\
\text { - Centralized and sliced network identification } \\
\text { - QoS for slicing in vehicular networks } \\
\text { - Support data analytics methods }\end{array}$ \\
\hline
\end{tabular}

\section{Future Smart Cars}

Future cars are coming, albeit less quickly than technologies would allow. In recent years, however, automotive companies have quickly recovered lost time, and now the revolution seems to be genuinely befalling. Connected cars, self-driving cars, electric cars, remote diagnostic systems, remote control, artificial intelligence, smart grid, vehicle to grid, infotainment systems, carpooling, car-sharing, car as a service (CaaS), V2V communications, and integration with the smart home are now terminology and technologies widely transferred from science to reality and everyday life. Beyond these names, it is interesting to hypothesize how the car will be in 5, 10, or 20 years.

According to a report presented by Goldman Sachs [37], the outcomes promised by the car revolution will be noticed shortly, starting from 2025. The key to the development will be technology, but the features that drive the change will be four. Specifically, the car of the future will be green, because both consumers and governments are putting pressure on the car industry to reduce $\mathrm{CO} 2$ emissions, which currently represent $20 \%$ of total gas for transport greenhouse. Another fundamental argument will be convenience because, with the increase in the urban population $(+50 \%$ from 2010 to 2025), traffic grows dramatically, and while cars are unused $95 \%$ of the time, the costs of ownership also increase [38]. This situation will offer several business opportunities also in terms of sharing economy. The car of 2025 will see a development in safety, which is also necessary due to the aging of the population (and therefore also motorists), and will undoubtedly also have to be affordable [39]. The car market, according to the report [37], will be almost stable in developed nations but will notice a dizzying expansion in emerging countries, where, in $2025,70 \%$ of the new cars produced globally will be sold. In short, according to Goldman Sachs, in six years, the car will be smarter and more 
functional, with high-efficiency engines and lighter materials [40]. All this can be achieved not only thanks to 5G, which will allow the car to communicate in real-time with the surrounding environment, but also to increasingly advanced and reliable autonomous driving systems. The car industry will also evolve, driven by competition from new tech companies. In the same way, the motorist is destined to change because he will look differently at the car, no longer as a status symbol, but as an instrument to be shared and also used as a workplace and for entertainment.

By 2030, then, the revolution will go even further. According to the researchers of the IONIQ Lab Hyundai [41], in the next ten years, the car industry will be reshaped by 12 megatrends that are already starting to emerge: from the hyper-connected society, with the evolution of the IoT also applied to cars, to the aging of the population, which will require to study cars adapted to the needs of the over 65s. Another megatrend will concern ecology, with the production of cars driven only by eco-friendly electric and hybrid engines [42], and, therefore, what is called "multilayer composition"; that is, the combination of different industrial sectors that will collaborate with the automotive sector to intensify, thanks to new technologies (such as augmented reality and virtual reality), the driving experience [43]. There will be a possibility to provide personalized information to users based on biological and emotional signals. Motorists will have an experience of hyper-individual mobility with personalized in-car services adapted to their emotional state in real-time. In order to attract and impress customers, the automotive industry will also have to be increasingly innovative and creative in proposing car models that are fusions of art and technology, unattainable for standardized creative algorithms of artificial intelligence [44]. The continuous technological evolution could increase anxiety and chaos in society, and the car will no longer become only be a vehicle of going from one place to another, but also a place of escape. The interiors will, therefore, be user-friendly. Nevertheless, at the same time, the expansion of the sharing economy will lead to the implementation of on-demand mobility services and platforms capable of maximizing the user experience. With the growth of self-driving cars, it will be increasingly urgent to establish ethical rules for mobility systems to ensure safety, control, and efficiency. However, traffic problems will grow exponentially due to the expansion of cities, with $70 \%$ of the world population living in urban areas. The car and mobility will also have to be rethought [45].

Ten years later, in 2040, cars will undergo a new transformation. By that date, it is expected that the combustion engines will disappear for the exclusive use of electricity. According to Mike Ramsey [46], director of Gartner's research group specializing in smart mobility and the automotive industry, during an interview with $\mathrm{CNBC}$, private cars will once again become a luxurious status symbol. With the expansion of the sharing economy and the increase in management costs, commuters will tend to use shared mobility services, or in the worst-case scenario, to buy second-hand cars, and the car will become, in the majority part of the cases, a service (CaaS) and no longer an asset. The more advanced cars will instead have swivel seats to create working spaces inside them, more advanced HUD screens than those available today, biometric systems rather than keys and locks, commands activated by gestures and voice control, and a multimedia center that will become the core of the car's infotainment system (and which will also be connected to sensors and devices of the smart home), whereby driving will become the responsibility of the on-board computer ultimately. According to Ramsey, it will be possible to get on board and communicate to the car where to go, and the car will subsequently communicate with the roads, other cars, and infrastructure not only to calculate the best route for the passenger but also for any other commuters to "gather" on the way. Once the passengers are delivered to their destination, the car will automatically retire to the nearest charging station, waiting to be called back to bring the passengers home (or in the post-work entertainment facilities). Alternatively, if enabled, the car will continue its journey to support the autonomous fleets of transport or delivery services. 


\subsection{Advanced Driver Assistance Systems}

In recent years, the attention of vehicle security developers has extended from passive safety systems (such as airbags, seat belts, and impact resistance, to name a few), which are already consolidated, to advanced active safety practices, mainly designed to prevent dangerous situations and accidents. Advanced driver assistance systems (ADAS) are electronic driver assistance systems developed to improve car safety $[47,48]$. ADAS is an abbreviation that indicates and groups a series of devices that can assist and facilitate driving the car even in emergencies. ADAS include various devices, such as the rain sensors to activate the windscreen wipers automatically, the twilight sensor for the automatic switching on of the lights, the adaptive cruise control to adjust the speed based on traffic, the automatic emergency braking, parking sensors, lane change warning systems, and automatic signal recognition systems. Many of these components are installed on newly homologated cars and are described more detail in the following subsections.

It is useful to note that the Euro NCAP [49] protocol has included several ADAS systems, including autonomous emergency braking, assisted speed control systems, lane maintenance, and signage detection systems, but these are only the first steps towards autonomous driving of the future. CSI [50], center of excellence in the automotive sector concerning test and acceptance, also participates in the drafting of the new protocols. CSI, as an accredited Euro NCAP laboratory (there are only seven in Europe), works in synergy with all the members in the system to identify what the future security requirements will be. Since 1997, much has been done regarding the improvement of the safety of occupants and vulnerable road users through the requirements of both the law and voluntary protocols, such as Euro NCAP, which, according to the ETSC PIN Report [51], have helped save since those years over 78,000 lives. The security intention is also linked to a political direction. The European Commission is communicating several directives, including the "Europe on the move" plan [52], to improve road safety through technological innovation and automation. The ultimate goal is to halve road accidents in Europe in the coming years, from 31,000 in 2010 to around 15,000.

\subsubsection{Park Assist}

The park assist is equipped with ultrasonic sensors used to identify a space suitable for parking the car, parallel or perpendicular to the direction of travel, comb, or herringbone [53]. Generally, the system is activated by pressing with a suitable button on the dashboard allowing the device to start scanning the surrounding space in search of a parking space. The driver can communicate to the control unit from which side it is preferred to park by inserting the appropriate signal light. Once it is located a place suitable for the size of the car, i.e., about $80 \mathrm{~cm}$ wider or longer, the control unit displays a message on display. The starting position of the maneuver is shown to the driver that engages the reverse gear once the proper place is reached. At this point, the system takes over the steering and indicates to the driver, via the onboard systems, the display, and voice synthesizer, how to manage the accelerator or the brake for reverse in order to park correctly.

The most advanced models autonomously also manage the accelerator, brake, and transmission, if automatic. The driver must pay attention to the maneuver because some obstacles may not be recognized by the automatic system, such as posts, concrete blocks, pedestrians, and, therefore, it may be necessary to intervene personally on the brake to stop the vehicle. Besides, the number of maneuvers and the time required for parking depend on the available space: the narrower space, the more time and maneuvers will be needed.

\subsubsection{Adaptive Cruise Control}

Adaptive cruise control (ACC) is a handy electronic device, especially on a highway, which helps to maintain constant speed but respecting a minimum preset distance compared to the vehicle in front [54-56]. It is adaptive because it automatically adapts the car's speed to that of the other car traveling in front. If the car in front travels, for instance, at $90 \mathrm{~km} / \mathrm{h}$, and the ACC has been set at 
$130 \mathrm{~km} / \mathrm{h}$, through a system of radar sensors, and possibly a camera, it cuts off the engine power until the car slows down to a speed of $90 \mathrm{~km} / \mathrm{h}$ with a safety distance from the front one that remains fixed. When the car in front accelerates, passing (for instance) from $90 \mathrm{~km} / \mathrm{h}$ to $180 \mathrm{~km} / \mathrm{h}$, the vehicle will accelerate again up to the set speed of $130 \mathrm{~km} / \mathrm{h}$. When the vehicle is equipped with an automatic transmission, the system can even brake it until it stops completely.

\subsubsection{Autonomous Emergency Braking}

Since 2020, the European Parliament has decided that automatic emergency braking will be mandatory on newly registered cars [57]. This measure is a substantial novelty for the improvement of road safety, i.e., the mandatory introduction of a critical ADAS system, such as that of emergency braking, in all new cars that will be sold in Europe. This system is the so-called autonomous emergency braking (AEB) [58], which must work up to $60 \mathrm{~km} / \mathrm{h}$ and be installed on light commercial vehicles. Automatic braking is now included in small cars as well. It is a beneficial technology, both in the city and on suburban roads and highways to avoid accidents due to distractions and little attention being paid to driving.

Emergency braking works thanks to the camera and radar sensors positioned on the front of the vehicle. In addition to vehicles, it also intercepts obstacles, pedestrians, cyclists, and even animals [59]. Once the potential danger has been identified, it emits an audible and visual signal inside the passenger compartment to alert the motorist and then works on the car's brakes. According to the European Parliament's legislation, the AEB will have to operate at least up to $60 \mathrm{~km} / \mathrm{h}$, also be mounted on vans, and will have to meet some technical requirements, which will prove its effectiveness even in extreme situations. Considering the United Nations Economic Commission for Europe's forecasts, AEB should significantly decrease the percentage of victims of road accidents, which, according to 2016, it did by $38 \%$. Emergency braking is already mandatory in Japan, which was the first region in the world to equip cars with this technology. Two other states, such as China and the United States, actually have decided to wait, while in India the obligation will start from 2022.

\subsubsection{Lane Assist}

The generic definition of lane assist identifies a family of increasingly popular safety devices that fall into the ADAS [60]. Through a camera generally positioned behind the windshield, near the internal rearview mirror, the lane assist detects the continuous and dotted lines on the asphalt and identifies the lane traveled by car. When the latter tends to diverge from the ideal trajectory, giving the idea to the sensors that an exit is not signaled from the lane, the system intervenes promptly. In the case of the lane departure warning [61], the electronic control unit activates an acoustic signal or a vibration of the seat or steering wheel to bring the driver's attention back to what is happening. In the case of lane keep assist [62], the device also comes into play to bring the car back to the center of its lane. This goal is reached thanks to precise data input to the steering and the braking system, with an action that can be selective on the disc of each wheel. Both the lane departure warning and the lane keep assist can be deactivated. Neither of the two devices can operate in the absence of horizontal signs or below a specified minimum speed.

Lane assist limits the risk of unintentional exit from the lane, which is often among the causes of road accidents. The electronics are, therefore, able to remedy the driver's distractions, but they must not, however, place undue reliance on technology support. The sudden failure of the signs could make the device inactive, and the attention should be constant. It is no coincidence that even the most advanced systems that intervene to keep the car in lane emit an alarm and are deactivated if they do not detect the presence of at least one hand on the steering wheel and the active participation of the driver in driving. 


\subsubsection{Traffic Sign Recognition}

Traffic sign recognition can detect, for instance, speed limits, but also prohibitions on access and overtaking. A video camera, located on the inside of the windscreen (in correspondence with the internal rearview mirror), registers the speed limits indicated on the road edges, but also those on the trestle portals or near construction sites. The data captured by the camera are compared with the information of the navigation system and displayed both on the instrument panel display and the infotainment screen [63]. Access and overtaking bans (including signs indicating termination) and other warnings are also noted. The camera, used for traffic sign recognition, allows manufacturers to integrate a wide range of driver assistance systems, improving safety on board.

Thanks to the traffic sign recognition, the driver is always well informed, in case a signal is missed, which can quickly happen with the frequent road sign variations. The system can also warn the driver with an audible and visual alarm if the indications of the signals are not respected. If the signs are covered or dirty, it may happen that, in certain circumstances, the system recognizes them only in a limited way. If the car proceeds with the cruise control active and the set speed is higher than the new limit, the system will automatically adapt the car speed to respect the signal.

\subsubsection{Future ADAS}

The first fundamental evolution of the ADAS, already taken into consideration by CSI tests, is the car's ability to recognize the three-dimensionality of the other vehicles on the road, favoring mutual recognition in the case of any relative trajectories (crossroads, overtaking, to mention some) and not only vehicles that run on parallel paths (classic column braking scenario). Concerning autonomous driving, the development of the related systems will allow the car to perform maneuvers progressively over the next few years until total autonomy, while requiring the presence of the driver ready to intervene in cases of need.

To date, almost all vehicles on the roads with ADAS systems, except in specific cases, settle on the levels between 0 and 2 of automation (level 2 is defined as "partial automation"-Figure 1), in which the systems merely support the driver without replacing it, but the direction is to create evermore significant and more integrated ADAS functions. Besides, systems capable of establishing an ever-increasing V2X dialogue are being studied. In the coming months, vehicles that perform high automation tasks may already circulate, with a driver who is present in the car but can take care of other activities (level 4). Finally, in the future, fully autonomous vehicles will circulate for which the autonomous driving will be able to replace the driver in all the commands necessary to drive the vehicle (level 5).

As part of its idea to make road transport smarter and more comfortable, the European Automobile Manufacturers' Association (ACEA) [64] has drawn up a checklist of laws and regulations that need to be established in place to make automated driving a reality in the European Union [65]. To this end, ACEA published its roadmap that contains a checklist for policymakers, which details the legislative framework that must be put in place at the national, European Union, and international levels, as well as a timeline outlining the steps towards deployment that must be initiated over the upcoming decades. In addition to establishing the right legal framework, policymakers need to update Europe's physical and digital road infrastructure to make it proper for automated driving. Large-scale and cross-border testing of automated systems on open roads across the European Union are always in demand. It is well known that automated driving will cause extensive renovations, so it is imperative to guarantee that society is ready for it. It is necessary to raise awareness among citizens and their elected representatives of what this means. As an enrichment to this purpose, the ACEA publication [65] describes precisely and visually the terminology, advantages, and implications of automated driving, as well as the research and development focus areas of this new ecosystem.

It is agreeable to conceive if the introduction of new ADAS will increase the cost of cars. To this end, the European Union is making available a ceiling of 450 million euros to be paid to the Member States to collaborate in the application of the regulation, thus avoiding the increase in list prices [66]. 


\subsection{Power Supply and Charging of Future Cars}

The abandonment of fossil fuels and the transition to electricity raise problems that could not be easy to solve. The distribution network must be able to withstand such a massive energy demand if electric cars replace the entire fleet of cars.Besides, in the province and small towns, it will be more likely that homes have a garage for the car (and therefore access to an electrical outlet), while in large cities it may be more difficult to recharge the car batteries. A massive public intervention will be essential to enhance both energy production (obviously from renewable sources; otherwise, the benefit of the "green" engine is lost by merely moving the emissions from the place of use to the place of energy production) and the recharge capacity.

Once the network is sufficiently extended, one of the solutions designed to avoid network overloads could be the vehicle-to-grid (V2G) [67]. This system provides the possibility for the electric operator who manages the columns to control the batteries of the cars being recharged so that they can be used both as "temporary accumulators" to store an excess of production and as "auxiliary batteries" to absorb energy to be fed into the grid if required. However, the system suffers from some criticisms. Above all, continuous charge-discharge cycles could wear massively on car batteries that are part of the network. The solution to this problem could be an algorithm developed by a researcher from the University of Warwick [68] that not only promises to safeguard the batteries but even to extend their useful life. Anyhow, several solutions in the literature have been proposed to try to address this problem $[69,70]$. Even if this problem can be solved, however, many more will still persist. For instance, the one from the autonomy of electric cars. The high-end ones exceed approximately $630 \mathrm{~km}$, but the most affordable ones do not reach 400. Another problem is that of charging times. Fortunately, in this case, the most recent electric car models allow for recharging enough energy in half an hour to travel another 200-250 km.

\subsection{The Future of Diesel}

While car manufacturers, partly driven by the growing concern for climate change, and partly (more realistically) by increasingly stern emissions stakes, now appear to be looking exclusively at electric engines for future cars. Diesel engines (perhaps hybridized), and not petrol ones, could lead in the challenge of moving toward electric ones. Among the leaders of this idea, it is possible to note Bosch, according to which diesel engines pollute even less than petrol engines [71].

In the meantime, at least in Europe, several governments (including the French and the British ones) have already established that cars with combustion engines can no longer be sold after 2040, while other countries (including Italy and Spain) are considering stopping and others have even anticipated the ban: in Norway in 2025 and Holland in 2030 [72]. However, Mercedes-Benz experts have pointed out that diesel is the most efficient combustion engine, so that it will remain active for a long time-well beyond 2025. The German Bosch and Mercedes, therefore, highlight that diesel is not intended to disappear. Moreover, the Germans Audi and Volkswagen, despite the commitment to the electricity, are continuing to invest hundreds of millions on the development of more efficient diesel engines with lower emissions. Anyhow, there are ongoing experiments in Germany and Italy with the electrification of highway stretches to allow trucks equipped with pantographs to proceed with electricity like trains. Despite the development and the growing diffusion of liquefied natural engines gas (LNG), almost all massive transport fleets are equipped with diesel engines. Furthermore, so far, no one has questioned the fact that trucks, vans, and buses will continue to use these engines.

\section{Conclusions}

Considering the evolution of the engines, which will be influenced not only by technical choices but also by federal guidelines and by features such as incentives and disincentives, the other fundamental characteristics of future cars seem outlined. Based on some future prospects, it is likely that the car will lose, at least in part, its status symbol function and will be transformed from a means of 
transport into an extension of the living space. Future smart cars will be necessary for mobility needs, but they can also be used, as needed, as offices, as relaxation areas, as socializing spaces, and as sorts of "protective bubble" to escape from the chaos of the surrounding environment [73]. According to experts, self-driving cars will overwhelmingly become part of daily life, probably already in the next decade. Undoubtedly, in the next twenty years, they could contribute to decreasing traffic, or at least make it smoother and more manageable thanks to the continuous interaction between the car and the smart city, the streets, the signs, and the surrounding environment. Furthermore, considering that driving will be controlled by artificial intelligence, emissions (in the case of combustion engines) and energy consumption (in the case of electric engines) will also be more contained and optimized. In parallel, an increase in productivity can be obtained using the travel time to work or to relax. At the same time, there will be a reduction in stress due to driving, and an increase in safety, both for car occupants and for pedestrians and cyclists. Consequently, the transformation of the car from an asset to an on-demand service could also allow achieving economic savings.

However, the future smart car may not only bring advantages. For instance, more frequent failures and anomalies will have to be addressed. Generally, the more complex a system becomes, the more it is inclined to breakdowns and unexpected problems. Unmistakably, the intervention of highly specialized technical personnel will be required to solve these problems. Furthermore, as already mentioned, considering that the current trend is focused on a massive shift of research and investments towards the electric car, when there will be millions and millions of electric vehicles, on the one hand, the pollution in cities will be reduced. However, it will be necessary to deal with the increase in energy demand. As a result, massive investments in renewables will be needed, and there will be an increase in the demand for materials, fundamental for the production of batteries. At the end of their lives, the latter must be disposed of to avoid becoming a dangerous source of pollution [74].

Sometimes, however, criticism concerning future cars trespasses on technophobia or downright on "technological Luddism". For instance, several experts fear that the unstoppable technological evolution will lead to an intensification of the polarization of wealth. Specifically, the whole population will not have the opportunity to afford a technologically advanced car with all the necessary safety equipment, and perhaps, this could even lead to a new class struggle. Many individuals may not be able to adapt to technology's progress and will remain in a sort of limbo of social exclusion. Others currently complain about privacy problems because, using hyperconnected cars, no one will really be "invisible" but will always be identifiable within the vast global network. Other criticisms are raised by those who recognize in the advancement of artificial intelligence, necessary for autonomous driving, a threat to their economic solidity, and their workplaces; all those who have made a profession of driving fear that self-driving fleets will replace them. Another problem that must be addressed carefully is cyber-attacks. If the self-driving cars are hacked and controlled by attackers, chains of catastrophic road accidents could be created, or the cars could be transformed into remote-controlled "bullets" and thrown against the crowd or strategic objectives.

Finally, there are also doubts from the philosophical and moral points of view on future smart cars; see the so-called "moral machine experiment" [75,76]. The study focuses on the behavior of the vehicle when it is impossible to avoid an accident and the vehicle must choose whether to crash, for instance, against a concrete wall—killing the passenger, or to overwhelm a passerby; whether to run over and kill a child or an older adult; or between a tramp and a man in a suit and tie; or between a pregnant woman and a man. The results of the research show that people would prefer to run over, in order, a cat, a criminal, a dog, an older man, an older woman, a tramp, a fat man, and a fat woman, while avoiding at all costs to run over a stroller, a girl, a boy, a pregnant woman, a male doctor, and a female doctor. The authors of [76] recognize that ethical inclinations may differ over education, but their fundamental point is that the contemporary moral machine experiment paradigm is nearly uncaring regarding inclinations for equality, notwithstanding participant culture. Moreover, the authors acknowledge that people frequently do prejudge based on personal traits, as sexism, classism, racism, and ageism all illustrate. Nonetheless, also, people who inevitably behave 
to preserve inequality often explicitly espouse ideas of equality. Consequently, it is necessary to evaluate whether it is right to transmit the same "instructions" to artificial intelligence that may have to decide in a real situation. Notwithstanding, this question has not yet been answered, but the latter will be fundamental, both from legal responsibility and from the insurance position, when the self-driving cars will be present on a large scale in the streets. It is clear that self-driving car accidents are an inevitability, but the variety of accidents that ethically hurt the public and hinder the industry are not. Consequently, it appears crucial to predict how society will respond to the ethical choices programmed into these smart vehicles. Considering that any arrangement employed in assembling these decisions will have its inclinations and weaknesses, the methodological heterogeneity and the widespread involvement of psychologists will be crucial to approaching that goal.

Author Contributions: The authors contributed equally to this work. All authors have read and agreed to the published version of the manuscript.

Funding: This research received no external funding.

Acknowledgments: This work was related to the D.D. 407 of 27 February 2018 "AIM-Attrazione e Mobilità Internazionale" issued by the Italian Ministry of Education, University, and Research in implementation of Action I.2 "Mobilità dei Ricercatori" Asse I-PON R\&I 2014-2020, taking into account the written amendment procedure of the PON R\&I 2014-2020, pursuant to articles 30 and 90 of Regulation (EU) 1303/2013 started on 21 February 2018 as well as the relevant implementation regulations.

Conflicts of Interest: The authors declare no conflict of interest.

\section{References}

1. Park, J.; Nam, C.; Kim, H.J. Exploring the key services and players in the smart car market. Telecommun. Policy 2019, 43, 101819; ITS Seoul 2018. [CrossRef]

2. Agriesti, S.; Studer, L.; Marchionni, G.; Gandini, P.; Qu, X. Roadworks warning-closure of a lane, the Impact of C-ITS messages. Infrastructures 2020, 5, 27. [CrossRef]

3. Kirk, R. Cars of the future: The Internet of Things in the automotive industry. Netw. Secur. 2015, 2015, 16-18. [CrossRef]

4. Arena, F.; Pau, G.; Collotta, M. A survey on driverless vehicles: From their diffusion to security features. J. Internet Serv. Inf. Secur. (JISIS) 2018, 8, 1-19.

5. Edwards, C. Car safety with a digital dashboard. Eng. Technol. 2014, 9, 60-64. [CrossRef]

6. Ogando-Martinez, A.; Troncoso-Pastoriza, F.; Eguia-Oller, P.; Granada-Alvarez, E.; Erkoreka, A. Model calibration methodology to assess the actual lighting conditions of a road infrastructure. Infrastructures 2020, 5, 2. [CrossRef]

7. Menarini, M.; Marrancone, P.; Cecchini, G.; Bazzi, A.; Masini, B.; Zanella, A. TRUDI: Testing environment for vehicular applications running with devices in the loop. In Proceedings of the 2019 IEEE International Conference on Connected Vehicles and Expo (ICCVE), Graz, Austria, 4-8 November 2019; IEEE: Piscataway, NJ, USA, 2019. [CrossRef]

8. Arena, F.; Ticali, D. The development of autonomous driving vehicles in tomorrow's smart cities mobility. AIP Conf. Proc. 2018, 2040, 140007. [CrossRef]

9. Inkoom, S.; Sobanjo, J.; Chicken, E. Competing risks models for the assessment of intelligent transportation systems devices: A case study for connected and autonomous vehicle applications. Infrastructures 2020, 5, 30. [CrossRef]

10. Kurebwa, J.G.; Mushiri, T. Internet of things architecture for a smart passenger-car robotic first aid system. Procedia Manuf. 2019, 35, 27-34. [CrossRef]

11. Wang, S.; Yuan, J.; Li, X.; Qian, Z.; Arena, F.; You, I. Active Data Replica Recovery for Quality-Assurance Big Data Analysis in IC-IoT. IEEE Access 2019, 7, 106997-107005. [CrossRef]

12. Ross, P.E. Robot, you can drive my car. IEEE Spectr. 2014, 51, 60-90. [CrossRef]

13. Khan, A.M.; Bacchus, A.; Erwin, S. Policy challenges of increasing automation in driving. IATSS Res. 2012, 35, 79-89. [CrossRef]

14. Masini, B.M.; Silva, C.M.; Balador, A. The Use of Meta-Surfaces in Vehicular Networks. J. Sens. Actuator Netw. 2020, 9, 15. [CrossRef] 
15. Mordue, G.; Yeung, A.; Wu, F. The looming challenges of regulating high level autonomous vehicles. Transp. Res. Part Policy Pract. 2020, 132, 174-187. [CrossRef]

16. Kuutti, S.; Fallah, S.; Katsaros, K.; Dianati, M.; Mccullough, F.; Mouzakitis, A. A Survey of the State-of-the-Art Localization Techniques and Their Potentials for Autonomous Vehicle Applications. IEEE Internet Things J. 2018, 5, 829-846. [CrossRef]

17. Arena, F.; Pau, G.; Severino, A. A Review on IEEE 802.11 p for Intelligent Transportation Systems. J. Sens. Actuator Netw. 2020, 9, 22. [CrossRef]

18. Narayanan, S.; Chaniotakis, E.; Antoniou, C. Shared autonomous vehicle services: A comprehensive review. Transp. Res. Part Emerg. Technol. 2020, 111, 255-293. [CrossRef]

19. Pau, G.; Severino, A.; Canale, A. Special Issue "New Perspectives in Intelligent Transportation Systems and Mobile Communications towards a Smart Cities Context". Future Internet 2019, 11, 228. [CrossRef]

20. Arena, F.; Pau, G.; Severino, A. V2X Communications Applied to Safety of Pedestrians and Vehicles. J. Sens. Actuator Netw. 2020, 9, 3. [CrossRef]

21. Amazon's Echo Auto Makes Alexa Your Co-Pilot. Available online: https://www.cnet.com/news/amazonsecho-auto-makes-alexa-your-co-pilot/ (accessed on 15 May 2020).

22. Okumura, H. Human Centric AR VR Display and Interface Technologies for Automobile. IEEE Consum. Electron. Mag. 2019, 8, 60-61. [CrossRef]

23. Barakabitze, A.A.; Ahmad, A.; Mijumbi, R.; Hines, A. 5G network slicing using SDN and NFV: A survey of taxonomy, architectures and future challenges. Comput. Netw. 2020, 167, 106984. [CrossRef]

24. Wang, H.; Wang, L.; Zhou, Z.; Tao, X.; Pau, G.; Arena, F. Blockchain-Based Resource Allocation Model in Fog Computing. Appl. Sci. 2019, 9, 5538. [CrossRef]

25. Muhammad, M.; Safdar, G.A. Survey on existing authentication issues for cellular-assisted V2X communication. Veh. Commun. 2018, 12, 50-65. [CrossRef]

26. Yuan, W.; Li, S.; Xiang, L.; Ng, D.W.K. Distributed Estimation Framework for Beyond 5G Intelligent Vehicular Networks. IEEE Open J. Veh. Technol. 2020, 1, 190-214. [CrossRef]

27. Bazzi, A.; Cecchini, G.; Menarini, M.; Masini, B.M.; Zanella, A. Survey and Perspectives of Vehicular Wi-Fi versus Sidelink Cellular-V2X in the 5G Era. Future Internet 2019, 11, 122. [CrossRef]

28. Arena, F.; Pau, G. An Overview of Vehicular Communications. Future Internet 2019, 11, 27. [CrossRef]

29. Bazzi, A.; Zanella, A.; Masini, B. A distributed virtual traffic light algorithm exploiting short range V2V communications. Ad Hoc Netw. 2016, 49, 42-57. [CrossRef]

30. Yuan, Y.; Lu, Y.; Wang, Q. Adaptive forward vehicle collision warning based on driving behavior. Neurocomputing 2019. [CrossRef]

31. Becic, E.; Edwards, C.J.; Manser, M.P.; Donath, M. Aging and the use of an in-vehicle intersection crossing assist system: An on-road study. Transp. Res. Part Traffic Psychol. Behav. 2018, 56, 113-122. [CrossRef]

32. Zafri, N.; Rony, A.; Adri, N. Analysis of pedestrian crossing speed and waiting time at intersections in Dhaka. Infrastructures 2019, 4, 39. [CrossRef]

33. Bazzi, A.; Zanella, A.; Cecchini, G.; Masini, B. Analytical investigation of two benchmark resource allocation algorithms for LTE-v2v. IEEE Trans. Veh. Technol. 2019, 68, 5904-5916. [CrossRef]

34. Chen, T.; Liu, K.; Wang, Z.; Deng, G.; Chen, B. Vehicle forward collision warning algorithm based on road friction. Transp. Res. Part Transp. Environ. 2019, 66, 49-57. Special Issue on Electromobility for Green Transportation Systems and Sustainable Environment. [CrossRef]

35. Payre, W.; Diels, C. I want to brake free: The effect of connected vehicle features on driver behaviour, usability and acceptance. Appl. Ergon. 2020, 82, 102932. [CrossRef]

36. Busari, S.A.; Huq, K.M.S.; Mumtaz, S.; Rodriguez, J. Terahertz Massive MIMO for Beyond-5G Wireless Communication. In Proceedings of the ICC 2019-2019 IEEE International Conference on Communications (ICC), Shanghai, China, 20-24 May 2019; pp. 1-6.

37. Cars 2025. Available online: https://www.goldmansachs.com/insights/technology-driving-innovation/ cars-2025/ (accessed on 15 May 2020).

38. Policarpo, M.; Aguiar, E. How self-expressive benefits relate to buying a hybrid car as a green product. J. Clean. Prod. 2019, 252, 119859. [CrossRef]

39. Tesoriere, G.; Canale, A.; Severino, A.; Mrak, I.; Campisi, T. The management of pedestrian emergency through dynamic assignment: Some consideration about the "Refugee Hellenism" Square of Kalamaria (Greece). AIP Conf. Proc. 2019, 2186, 160004. [CrossRef] 
40. Tesoriere, G.; Campisi, T.; Canale, A.; Severino, A.; Arena, F. Modelling and simulation of passenger flow distribution at terminal of Catania airport. AIP Conf. Proc. 2018, 2040, 140006. [CrossRef]

41. 12 Trends that Will Shape the Future of the Car Industry by 2030. Available online: https://www. hyundai.news/eu/stories /12-trends-that-will-shape-the-future-of-the-car-industry-by-2030/ (accessed on 15 May 2020).

42. Kim, J.; Kim, Y.; Choi, W.; Ahn, K.Y.; Song, H.H. Analysis on the operating performance of 5-kW class solid oxide fuel cell-internal combustion engine hybrid system using spark-assisted ignition. Appl. Energy 2020, 260, 114231. [CrossRef]

43. Giliberto, M.; Arena, F.; Pau, G. A fuzzy-based Solution for Optimized Management of Energy Consumption in e-bikes. J. Wirel. Mob. Netw. Ubiquitous Comput. Dependable Appl. (JoWUA) 2019, 10, 45-64.

44. Fritzsche, R.; Richter, A.; Putz, M. Automatic Adjustment of Car Body Fixtures Using Artificial Intelligence. Procedia CIRP 2017, 62, 600-605. [CrossRef]

45. Tuominen, A.; Rehunen, A.; Peltomaa, J.; Mäkinen, K. Facilitating practices for sustainable car sharing policies-An integrated approach utilizing user data, urban form variables and mobility patterns. Transp. Res. Interdiscip. Perspect. 2019, 2. [CrossRef]

46. What Will the Car of 2040 Be Like? Available online: https://www.theguardian.com/technology/2017/jul/ 26/what-will-future-car-of-2040-be-like-luxury (accessed on 15 May 2020).

47. Viktorova, L.; Sucha, M. Learning about advanced driver assistance systems-The case of ACC and FCW in a sample of Czech drivers. Transp. Res. Part Traffic Psychol. Behav. 2019, 65, 576-583. [CrossRef]

48. Chen, H.; Zhao, F.; Huang, K.; Tian, Y. Driver Behavior Analysis for Advanced Driver Assistance System. In Proceedings of the 2018 IEEE 7th Data Driven Control and Learning Systems Conference (DDCLS), Enshi, China, 25-27 May 2018; pp. 492-497.

49. The European New Car Assessment Programme. Available online: https://www.euroncap.com/en (accessed on 15 June 2020).

50. CSI: Certification and Testing. Available online: http:/ / www.csi-spa.com/en/ (accessed on 15 June 2020).

51. ETSC Road Safety Performance Index (PIN). Available online: https:/ / etsc.eu/projects/pin/ (accessed on 15 June 2020).

52. Europe on the Move: Commission Takes Action for Clean, Competitive and Connected Mobility. Available online: https: / / ec.europa.eu/transport/modes/road/news/2017-05-31-europe-on-the-move_en (accessed on 15 June 2020).

53. Xu, M.; Zhen, Y.; Zhao, K. The Application and Control Optimization of Electronic Park Brake in the Park Assist. In Proceedings of the 2016 Eighth International Conference on Measuring Technology and Mechatronics Automation (ICMTMA), Macau, China, 11-12 March 2016; pp. 675-680.

54. Zhu, B.; Jiang, Y.; Zhao, J.; He, R.; Bian, N.; Deng, W. Typical-driving-style-oriented Personalized Adaptive Cruise Control design based on human driving data. Transp. Res. Part C Emerg. Technol. 2019, 100, $274-288$. [CrossRef]

55. Zhao, D.; Wang, B. Data-based vehicle adaptive cruise control: A review. In Proceedings of the 32nd Chinese Control Conference, Xi'an, China, 26-28 July 2013; pp. 7840-7845.

56. Chamraz, S.; Balogh, R. Two approaches to the adaptive cruise control (ACC) design. In Proceedings of the 2018 Cybernetics \& Informatics (K \& I), Lazy pod Makytou, Slovakia, 31 January-3 February 2018; pp. 1-6.

57. Road Safety: Commission Welcomes Agreement on New EU Rules to Help Save Lives. Available online: https:/ / ec.europa.eu/commission/presscorner/detail/en/IP_19_1793 (accessed on 15 June 2020).

58. Mimura, Y.; Ando, R.; Higuchi, K.; Yang, J. Recognition on trigger condition of autonomous emergency braking system. J. Saf. Res. 2020, 72, 239-247. [CrossRef] [PubMed]

59. Kovaceva, J.; Balint, A.; Schindler, R.; Schneider, A. Safety benefit assessment of autonomous emergency braking and steering systems for the protection of cyclists and pedestrians based on a combination of computer simulation and real-world test results. Accid. Anal. Prev. 2020, 136, 105352. [CrossRef]

60. Mahajan, H.S.; Bradley, T.; Pasricha, S. Application of systems theoretic process analysis to a lane keeping assist system. Reliab. Eng. Syst. Saf. 2017, 167, 177-183. [CrossRef]

61. Gaspar, J.G.; Brown, T.L. Matters of State: Examining the effectiveness of lane departure warnings as a function of driver distraction. Transp. Res. Part Traffic Psychol. Behav. 2020, 71, 1-7. [CrossRef] 
62. Basjaruddin, N.C.; Suhendar, K.; Saefudin, D.; Aryani, S.A Lane Keeping Assist System based on fuzzy logic. In Proceedings of the 2015 International Electronics Symposium (IES), Surabaya, Indonesia, 29-30 September 2015; pp. 110-113. [CrossRef]

63. Zhou, S.; Deng, C.; Piao, Z.; Zhao, B. Few-shot traffic sign recognition with clustering inductive bias and random neural network. Pattern Recognit. 2020, 100, 107160. [CrossRef]

64. ACEA. Available online: https: / / www.acea.be (accessed on 15 June 2020).

65. Roadmap for the Deployment of Automated Driving in the European Union. Available online: https: / / www.acea.be/publications / article/roadmap-for-the-deployment-of-automated-driving-in-theeuropean-union (accessed on 15 June 2020).

66. Europe on the Move: Commission Completes its Agenda for Safe, Clean and Connected Mobility. Available online: https:/ / ec.europa.eu/transport/modes/road/news/2018-05-17-europe-on-the-move3_en (accessed on 15 June 2020).

67. Solanke, T.U.; Ramachandaramurthy, V.K.; Yong, J.Y.; Pasupuleti, J.; Kasinathan, P.; Rajagopalan, A. A review of strategic charging-discharging control of grid-connected electric vehicles. J. Energy Storage 2020, 28, 101193. [CrossRef]

68. Clean Energy Stored in Electric Vehicles to Power Buildings. Available online: https://warwick.ac.uk/ newsandevents/pressreleases/clean_energy_stored/ (accessed on 15 May 2020).

69. Zou, Y.; Zhao, J.; Gao, X.; Chen, Y.; Tohidi, A. Experimental results of electric vehicles effects on low voltage grids. J. Clean. Prod. 2020, 255, 120270. [CrossRef]

70. Das, H.; Rahman, M.; Li, S.; Tan, C. Electric vehicles standards, charging infrastructure, and impact on grid integration: A technological review. Renew. Sustain. Energy Rev. 2020, 120, 109618. [CrossRef]

71. The Future of Diesel. Available online: https://www.bosch-mobility-solutions.com/en/highlights/ powertrain-and-electrified-mobility/the-future-of-diesel/ (accessed on 15 May 2020).

72. Ghahari, S.; Assi, L.; Carter, K.; Ghotbi, S. The Future of Hydrogen Fueling Systems for Fully Automated Vehicles; American Society of Civil Engineers (ASCE): Reston, VA, USA, 2019; pp. 66-76. [CrossRef]

73. Tesoriere, G.; Campisi, T.; Canale, A.; Severino, A. The effects of urban traffic noise on children at kindergarten and primary school: A case study in Enna. AIP Conf. Proc. 2018, 2040, 140005. [CrossRef]

74. Pau, G.; Campisi, T.; Canale, A.; Severino, A.; Collotta, M.; Tesoriere, G. Smart Pedestrian Crossing Management at Traffic Light Junctions through a Fuzzy-Based Approach. Future Internet 2018, 10, 15. [CrossRef]

75. Awad, E.; Dsouza, S.; Kim, R.; Schulz, J.; Henrich, J.; Shariff, A.; Bonnefon, J.F.; Rahwan, I. The Moral Machine experiment. Nature 2018, 563, 59-64. [CrossRef]

76. Bigman, Y.E.; Gray, K. Life and death decisions of autonomous vehicles. Nature 2020, 579, E1-E2. [CrossRef] [PubMed]

(C) 2020 by the authors. Licensee MDPI, Basel, Switzerland. This article is an open access article distributed under the terms and conditions of the Creative Commons Attribution (CC BY) license (http://creativecommons.org/licenses/by/4.0/). 